\title{
ANÁLISE DA CAPACIDADE DE EXPLICAÇÃO DOS INVESTIMENTOS DAS EMPRESAS BRASILEIRAS DE CAPITAL ABERTO ATRAVÉS DO MODELO DO ACELERADOR
}

\section{EDSON LUIS KAMMLER}

Prof. Ms. da Faculdade de Itapiranga - SC

Coord. do Curso de Ciências Contábeis da Faculdade Concórdia - SC

E-mail: edsonkammler@hotmail.com

\section{TIAGO WICKSTROM ALVES}

Professor Titular da UNISINOS - RS

E-mail: twa@mercado.unisinos.br

\section{RESUMO}

Este artigo busca analisar a capacidade de explicação dos investimentos das empresas brasileiras de capital aberto através do Modelo do Acelerador modificado. A alteração feita no modelo foi a substituição dos gastos de consumo agregado, ou do estoque de capital do modelo básico, pelo valor das vendas das empresas. Utilizou-se o método dos mínimos quadrados ordinários em corte transversal para estimar os parâmetros do modelo. A aplicação, para a amostra selecionada, da análise referida permitiu verificar uma forte explicação dos gastos de investimentos com o nível de vendas. Sendo assim, é possível, a partir desses resultados, estimar as alterações do investimento de um ano para o outro. Esse fato é extremamente relevante devido à simplicidade do modelo.

Palavras-chave: Modelo do Acelerador; Investimento.

\section{ABSTRACT}

This paper seeks to explain the investments made by Brazilian firms operating in the capital market, using a modified accelerator model. The modification done in the basic model was the substitution of either the aggregate consumption or the capital stock by the firms' sales value. The parameters of the model were estimated by ordinary least squares using cross-sections. The application of such analysis to the selected sample allowed us to verify a strong correlation between investment expenditures and sales level. Based on these results, we can estimate changes in investments from one year to another. This is extremely important due to the simplicity of the model.

Keywords: Accelerator Model; Investment. 


\section{INTRODUÇÃO}

O aumento do investimento é condição necessária para a elevação da taxa de crescimento da economia, pois é através dele que se amplia a capacidade de produção e se incorpora o progresso técnico via introdução de novos produtos e métodos de produção. Para aumentar a taxa de crescimento da economia através de um aumento dos investimentos é necessário superar certas dificuldades, a que o país não tem conseguido ao longo das últimas duas décadas. Uma medida é criar um ambiente favorável aos investimentos, o que implica duas coisas: gerar expectativas econômicas favoráveis em relação ao futuro e mobilizar fundos de longo prazo a taxas de juros compatíveis com o retorno adequado dos investimentos. (MERCADANTE, 2003).

As expectativas em relação ao futuro desempenham um papel fundamental nas decisões de investimentos, pois, quem decide, tenta projetar possíveis resultados para só depois tomar a decisão de investir ou não. Essas projeções representam um desafio, pois são feitas com base em expectativas que podem não se realizar, sendo que os maiores problemas ocorrem quando as projeções são muito otimistas.

Em estudo demonstrando o impacto da psicologia individual e coletiva nas decisões de investimentos, Daniel Kahneman ${ }^{1}$ concluiu que pelo menos $40 \%$ das pessoas tendem a ser muito otimistas na hora de fazer uma avaliação, o que significa que pelo menos $40 \%$ das pessoas podem tomar decisões erradas por isso. Segundo o autor, elas tendem a considerar quadros incompletos, ignorando os riscos e considerando apenas os fatores positivos, o que pode provocar graves erros no momento de investir (EXAME, 2003).

A pesquisa de Kahneman evidencia as dificuldades nas projeções e na escolha das melhores alternativas de investimentos. Como exemplo, um empresário pode optar por comprar uma nova máquina, ampliar ou até construir uma nova fábrica, ou mesmo, por aplicar o excedente no mercado financeiro. Contudo, não sabe, com certeza, qual investimento trará o maior retorno, pois suas projeções se baseiam numa função de probabilidade, que contém um elevado grau de subjetividade. Dessa forma, a empresa só terá a informação se o projeto escolhido foi rentável ou não após sua entrada em operação.

Nesse sentido, a decisão dos empresários em fazer investimentos produtivos depende das expectativas de longo prazo quanto ao fluxo de renda que os investimentos irão gerar em relação aos custos incorridos. No entanto, a precariedade das bases sobre as quais se tomam as decisões, conduz a que as expectativas de longo prazo sofram constantes revisões. Existe uma tendência de que elas sejam influenciadas por fatos que caracterizam uma situação presente $e$ que servem de referência para a construção de um quadro futuro (CASAGRANDE, 2002, p. 25-26).

Em função da importância das variáveis presentes na formação das expectativas é que se constrói a hipótese teórica deste trabalho, ou seja: temse como hipótese que o volume de vendas presente seja o fator determinante das expectativas futuras.

Ressalte-se o caráter determinante, pois existem $n$ fatores que influenciam as expectativas e as decisões de investimentos. Nesse sentido, Shapiro (1985, p. 298-299) considera que as variações nos investimentos ocorrem em função das expectativas, da mudança e inovação tecnológicas, do nível de renda e do produto, das variações no nível de renda e do produto e da taxa de juros. Todavia o autor afirma que a idéia de uma lista nada mais é do que uma simples conveniência e um número maior de fatores pode influenciar nas decisões de investimentos.

Sendo assim, tem-se como objetivo desta pesquisa aplicar o Modelo do Acelerador modificado, para verificar a relação das vendas com os investimentos.

Para um melhor entendimento deste trabalho, inicialmente descreve-se o Modelo do Acelerador e os procedimentos metodológicos utilizados e, na seqüência, analisam-se os resultados da aplicação do modelo.

\section{MODELO ACELERADOR DO INVESTIMENTO}

O Modelo de Acelerador é a teoria de investimento mais antiga ainda em uso empírico. A premissa desse modelo é a de que existe uma associação entre as mudanças na produção e os gastos com investimentos (SACHS; LARRAIN, 1995, p. 148). O modelo original afirmava que a taxa de investimento era proporcional à variação do Produto Nacional Bruto (DORNBUSCH; FISCHER, 1982, p. 210).

A relação entre a variação no nível de produto e o volume de gasto de investimento é conhecido como o princípio da aceleração. Na sua forma mais simples, o investimento (It) depende da variação do produto $(Y)$ do período anterior para o período atual, multiplicado pela relação capital- $\operatorname{produto}^{2}(\lambda)$,

\footnotetext{
${ }^{1}$ Daniel Kahneman ganhou o prêmio Nobel de Economia em 2002, pelo seu estudo sobre o impacto da psicologia individual e coletiva nas decisões de investimentos. ${ }^{2}$ A relação capital-produto pode ser entendida como a quantidade de unidades monetárias de capital necessária para produzir uma unidade monetária de produto por período de tempo (SHAPIRO, 1985, p. 332).
} 
também conhecido como acelerador (SHAPIRO, 1985 , p. 333). Nesse caso, a equação do investimento seria:

$$
I_{t}=\lambda\left(Y_{t}-Y_{t-1}\right)
$$

Percebe-se que qualquer variação do produto (Y) acarreta que o investimento (I) nesse período seja diferente do anterior, porém uma elevação ou baixa no nível de investimento afetará o nível de produto em períodos sucessivos.

Entretanto, essa é apenas uma dentre um grupo de possíveis funções do investimento que incorporam o princípio da aceleração. Uma outra função leva a que o acelerador seja aplicado unicamente a produtos de bens de consumo. Nesse caso, ter-seia a seguinte equação (SHAPIRO, 1985, p. 580):

$$
I_{t}=I_{a}+\lambda\left(C_{t}-C_{t-1}\right)
$$

em que:

$I_{a} \quad=$ é o investimento autônomo

$\stackrel{a}{C}_{t}=$ é o consumo total no período "t";

$C_{t-1}=$ é o consumo do período anterior;

$\lambda^{t-1}=$ é o acelerador.

Outras funções ainda, neste grupo, resultam da aplicação de uma forma defasada do princípio da aceleração em vez da forma empregada acima. Nesse caso, a equação seria a seguinte (SHAPIRO, 1985, p. 580):

$$
I_{t}=I_{a}+\lambda\left(C_{t-1}-C_{t-2}\right)
$$

Segundo Shapiro (1985, p. 580-581), a forma defasada parece ser a mais plausível, pois uma elevação no consumo do período corrente em relação ao do período precedente, pode demandar decisões empresariais tendentes a expandir os gastos com investimentos, porém os gastos não são simultâneos com o aumento no consumo que vierem a exigir esses investimentos. A função defasada proporciona um intervalo de tempo entre a decisão de investir e a efetivação dos gastos de investimento.

A principal crítica a esse modelo é que ele considera que não existe capacidade ociosa nas empresas. Segundo Shapiro (1985, p. 336), uma suposição indispensável para o funcionamento do princípio da aceleração é a de que as edificações e equipamentos existentes sejam plenamente utilizados. Porém, se a empresa tiver capacidade exce- dente, poderá não investir em decorrência de um aumento na produção.

Outras críticas são apresentadas por Jacinto (1997), entre elas, o número excessivamente reduzido de variáveis explicativas, o ajuste automático do investimento ao nível de produção e a não-possibilidade da distinção entre mudanças transitórias ou permanentes na produção.

Segundo Sachs e Larrain (1995, p. 150), apesar das limitações, o Modelo do Acelerador, na sua forma mais simples, descreve com precisão grande parte dos movimentos do investimento. Essa teoria geralmente é melhor que outras mais sofisticadas utilizadas para explicar e prever padrões reais de investimento.

O Modelo do Acelerador considera o investimento dependente da alteração da produção ou da variação do consumo e da relação capital-produto. Essas variáveis são passíveis de estimação. A variação do consumo poderia ser obtida através das vendas da empresa já que, segundo Shapiro (1985, p. 339), as decisões dos empresários, no que tange aos gastos com instalações, são baseadas, em parte, nas quantidades vendidas dos seus produtos. O termo "capital" utilizado no modelo poderia ser considerado como o ativo imobilizado, ou seja, o número de unidades monetárias de capital de que a empresa dispõe para produzir. Como produto podem ser consideradas as vendas do período. Essas são as alterações realizadas neste trabalho, conforme pode ser visto na seção a seguir.

\section{PROCEDIMENTOS METODOLÓGICOS}

No Modelo do Acelerador, testado empiricamente, fez-se a substituição das variáveis originais por dados obtidos a partir do balanço contábil. Sendo assim, a equação (1) foi transformada para:

$$
\operatorname{In} v_{t}=\beta_{0}+\beta_{l}\left(V_{t}-V_{t-1}\right)+\varepsilon_{t}
$$

em que:

$I n v_{t}=$ é a taxa de investimento no ano t;

$\beta_{0}=$ é o investimento autônomo;

$\beta_{1}$ = parâmetro que mede a sensibilidade do investimento para uma dada variação nas vendas;

$V_{t} \quad=$ são as vendas das empresas no ano $\mathrm{t}$;

$V_{t-1}=$ são as vendas das empresas no ano $\mathrm{t}-1$;

$\varepsilon_{t}=$ erro aleatório que capta todas as outras dependências sobre o investimento que não estão consideradas explicitamente.

\footnotetext{
${ }^{3}$ O investimento autônomo é a parte do investimento que não é afetada pelo nível de renda (SHAPIRO, 1985, p. 318-319).
} 
Sendo que para a amostra, foram selecionadas todas as empresas de capital aberto registradas na Bolsa de Valores de São Paulo - BOVESPA, com dados disponíveis no sistema Economática, e excluídas aquelas que não apresentaram as demonstrações financeiras em dezembro de 2001 e dezembro 2002. Após a exclusão, obteve-se o total de 272.

Cabe destacar que o modelo proposto já foi testado por Ndikumana (1999) e compreendeu o período de 1972 a 1991, limitado ao setor industrial dos Estados Unidos. Neste estudo, o autor considerou o crescimento das vendas como uma interpretação do efeito do acelerador. A conclusão foi de que o investimento pode ser explicado em $22,4 \%$ pela variação das vendas.

Para o investimento, foi considerada a variação percentual de 2001 para 2002 do valor do ativo imobilizado mais os estoques ${ }^{4}$. Isso levaria à determinação do investimento líquido que é a parte do investimento que aumenta o estoque de capital (SACHS; LARRAIN, 1995, p. 129) e que é a determinante nas teorias do investimento. Conforme Gordon (2000, p. 364), o investimento líquido (I) é a variação do estoque de capitais $(\Delta K)$ que ocorre em cada período, ou seja: $I=\Delta K=K_{t}-K_{t-1}$.

Na utilização da variação do valor do ativo imobilizado como investimento, podem ocorrer variações se as empresas fizerem reavaliações de seus bens. Na contabilidade, esse valor é lançado como acréscimo do bem, sendo considerado indevidamente como investimento do período. No entanto, do total das 455 empresas, somente 18 fizeram reavaliação, o que representa cerca de $4 \%$ do total; motivo pelo qual, esse fato não foi considerado na análise.

Embora o valor do investimento a ser identificado no Balanço Patrimonial das empresas seja uma questão controversa, que parece não ter consenso, essa decisão se justifica porque o investimento em imobilizado consiste nos gastos das empresas em maquinário durável, em equipamentos e estruturas tais como fábricas. Esses gastos contribuem para a maior parte do investimento. Os estoques compreendem as matérias-primas, os bens semi-acabados no processo de produção e os bens acabados em poder das empresas, que também podem ser considerados como investimentos (SACHS; LARRAIN, 1995, p. 129; DORNBUSCH; FISCHER, 1982, p. 154). Uma posição mais ampla sobre o investimento a ser identificado no balanço das empresas é dada por Matarazzo (2003, p. 396), que sugere a utilização do que se convencionou chamar de "ativo operacional", que representa o ativo total excluído das aplicações que não estão gerando lucro, como investimentos pré-operacionais, incentivos fiscais, participações em outras empresas. Já ludícibus (1998) e Marion (2002) consideram como investimento o ativo total médio. Assaf Neto (2002) considera como investimento o valor do ativo total excluído daqueles passivos considerados inerentes à atividade da empresa, como salários, fornecedores, impostos. Segundo o autor, é o montante que a empresa efetivamente investiu em seu negócio buscando esses recursos no mercado financeiro (empréstimos e financiamentos) e junto aos proprietários (sócios/ acionistas). No entanto, essas interpretações fogem da análise feita neste estudo.

As estimações foram realizadas através do método dos mínimos quadrados ordinários ${ }^{5} \mathrm{com}$ dados em corte transversal, ou cross-section como é conhecido na literatura inglesa, com utilização do software Eviews 3.0.

Para as vendas foram consideradas as receitas operacionais líquidas, obtidas nas demonstrações financeiras consolidadas das empresas dos anos de 2001 e 2002.

Espera-se o coeficiente de variação das vendas positivo, pois, teoricamente, existe uma relação positiva dessa variável com o investimento.

Com base nos resultados desse modelo foram realizadas diversas alterações com o objetivo de testar as possibilidades de relações existentes entre as variáveis. Foi testado como investimento a variação monetária do ativo imobilizado mais os estoques, bem como a variação percentual e em valores do ativo imobilizado. A variável crescimento das vendas também foi testada em variação percentual, bem como defasada num período; nesse caso, do ano 2000 para 2001.

\section{ANÁLISE DOS RESULTADOS}

Inicialmente, para a obtenção da regressão inicial, calculou-se o crescimento das vendas de 2001 para 2002. Realizando-se a regressão $\ln v_{2002}=\beta_{0}+$ $\beta_{1}\left(V_{2002}-V_{2001}\right)$, conforme a equação (4) com todas as 272 empresas, obteve-se o seguinte resultado:

\footnotetext{
${ }^{4}$ Para a obtenção dos valores do ativo imobilizado bem como dos estoques, em todas as estimações, foram utilizados os balanços consolidados das empresas.

${ }^{5} \mathrm{O}$ princípio dos mínimos quadrados procura ajustar a reta de tal forma que a soma dos quadrados das distâncias verticais de cada ponto à reta seja a menor possível.

Toma-se o quadrado das distâncias para evitar que grandes distâncias positivas sejam canceladas pelas negativas (HILL; GRIFFITS; JUDGE, 1999, p. 58).
} 
Tabela 1 - Resultados do teste do $I n v_{2002}=\beta_{0}+\beta_{1}\left(V_{2002}-V_{2001}\right)$, modelo utilizando todas as empresas

\begin{tabular}{lccccc} 
Modelo & Beta & t-estat. & Significância & Heteroscedasticidade & $\mathbf{R}^{2}$ \\
$\beta_{0}(2002)$ & 0,053482 & 2,897034 & Significante & 0,984533 & 0,008712 \\
$\beta_{1}(2002)$ & $1,05 \mathrm{E}-08$ & 1,540427 & Não Significante & 0,984362 & \\
\hline
\end{tabular}

Fonte: Elaborada pelos autores, com base nos dados da pesquisa.

Os resultados mostram um coeficiente da variável vendas positivo, consistente teoricamente, porém não significante, e quase nenhuma explicação da variação do investimento. Esse resultado pode ser decorrente do uso da variável independente (Inv) em taxa de variação do investimento em relação ao crescimento das vendas em valores monetários. Optou-se, então, por testar a seguinte equação:

$$
\operatorname{Inv} v_{t}=\beta_{0}+\beta_{1}\left(C V_{t-1 / t}\right)
$$

em que:

$I n v_{t}=$ é a taxa de investimento no ano $\mathrm{t}$;

$C V_{t-1 / t}=$ é a taxa de crescimento das vendas do ano $\mathrm{t}-1$ para o ano $\mathrm{t}$.

Os resultados com todas as 272 empresas da amostra, foram os seguintes:

Tabela 2 - Resultados do teste do $I n v_{2002}=\beta_{0}+\beta_{1}\left(C V_{2001 / 2002}\right)$, modelo utilizando todas as empresas

\begin{tabular}{lccccc} 
Modelo & Beta & $\mathbf{t}$ - estat. & Significância & Heteroscedasticidade & $\mathbf{R}^{2}$ \\
$\beta_{0}(2002)$ & 0,028592 & 1,421784 & Não Significante & 0,475793 & 0,037193 \\
$\beta_{1}(2002)$ & 0,174238 & 3,229559 & Significante & 0,472846 & \\
\hline
\end{tabular}

Fonte: Elaborada pelos autores, com base nos dados da pesquisa.

Essa regressão apresenta resultados melhores que a anterior, com um coeficiente angular positivo e com índice de explicação da variação do investimento pela variação das vendas de $3,7 \%$. O coeficiente de intercepto é não significante ao nível de $10 \%$. Testou-se, também, a variação do investimento em valores com a variação das vendas em valores. A equação testada foi a seguinte:

$$
\operatorname{Invv_{t}}=\beta_{0}+\beta_{l}\left(V_{t}-V_{t-1}\right)
$$

Tabela 3 - Resultados do teste do $\operatorname{lnv} v_{2002}=\beta_{0}+\beta_{1}\left(V_{2002}-V_{2001}\right)$, modelo utilizando todas as empresas

\begin{tabular}{lccccc}
\hline Modelo & Beta & $\mathbf{t}$ - estat. & Significância & Heteroscedasticidade & $\mathbf{R}^{2}$ \\
\hline$\beta_{0}(2002)$ & 48213,81 & 0,720633 & Não Significante & 0,00000 & 0,575941 \\
$\beta_{1}(2002)$ & 0,472009 & 19,14950 & Significante & 0,00000 & \\
\hline Fonte: Elaborada pelos autores com base nos dados da pesquisa. & & & \\
\hline
\end{tabular}

O coeficiente da variável crescimento das vendas é positivo, consistente teoricamente, com um índice de explicação da variação do investimento de $57,59 \%$ pela variação das vendas. O coeficiente de em que:

$I n v v_{t}=$ é a variação dos investimentos em valores monetários;

$V \quad=$ são as vendas das empresas no período $\mathrm{t}$ e $\mathrm{t}-1$.

Os resultados da regressão, utilizando todas as 272 empresas, foram os seguintes: intercepto é não significante ao nível de 10\% e o modelo apresenta problemas de heteroscedasticidade.

Segundo Gujarati (2000, p. 357), a heteroscedasticidade pode surgir como resultado da pre- 
sença de observações aberrantes (outliers). Uma observação é aberrante quando é muito diferente (ou muito pequena ou muito grande) das demais observações na amostra. A inclusão ou exclusão de tal observação pode alterar, significativamente, os resultados da análise de regressão. Em vista disso, optou-se por excluir as empresas que apresentaram uma variação no investimento superior ou inferior a um desvio padrão da média. Após as exclusões, re- sultaram 262 empresas para a análise, todavia também esse procedimento não resolveu o problema da heteroscedasticidade.

Optou-se, então, por dividir as empresas restantes em dois grupos: as que tiveram variação positiva no investimento e as que tiveram variação negativa, resultando uma amostra de 140 e 122 empresas, respectivamente. Para aquelas que investiram, os resultados foram os seguintes:

Tabela 4 - Resultados do teste do $I n v v_{2002}=\beta_{0}+\beta_{1}\left(V_{2002}-V_{2001}\right)$, modelo utilizando as empresas com variação positiva do investimento

\begin{tabular}{lccccc} 
Modelo & Beta & $\mathbf{t}$ - estat. & Significância & Heteroscedasticidade & $\mathbf{R}^{2}$ \\
$\beta_{0}(2002)$ & 92914,64 & 4,457602 & Significante & 0,171814 & 0,187154 \\
$\beta_{1}(2002)$ & 0,245792 & 5,636829 & Significante & 0,169150 & \\
\hline
\end{tabular}

Fonte: Elaborada pelos autores com base nos dados da pesquisa.

Essa regressão não apresentou problemas de heteroscedasticidade, com um coeficiente angular positivo, consistente teoricamente, e com um nível de explicação da variação do ativo imobilizado mais estoques de $18,71 \%$. Para as empresas com variação negativa, os resultados foram inconsistentes teoricamente.

A fim de melhorar os níveis de explicação da variação do investimento, realizaram-se outros testes, considerando como investimento somente a variação do ativo imobilizado, por representar os maiores gastos em investimentos realizados pelas empresas. As equações testadas foram as seguintes:

$$
I m_{t}=\beta_{0}+\beta_{l}\left(V_{t}-V_{t-1}\right)
$$

$$
\begin{gathered}
I m_{t}=\beta_{0}+\beta_{1}\left(C V_{t-1 / t}\right) \\
I m v_{t}=\beta_{0}+\beta_{l}\left(V_{t}-V_{t-1}\right)
\end{gathered}
$$

em que:

$I m_{t}=$ é a variação percentual do ativo imobilizado; $\operatorname{Im} v_{t}=$ é a variação em valores monetários do ativo imobilizado.

Nos testes com a variação percentual do investimento em relação ao crescimento das vendas em valores, não se obtiveram resultados significativos. $\mathrm{Na}$ utilização da variação percentual em ambos, os resultados com todas as 272 empresas foram os seguintes:

Tabela 5 - Resultados do teste do $I m_{2002}=\beta_{0}+\beta_{1}\left(C V_{2001 / 2002}\right)$, modelo utilizando todas as empresas

\begin{tabular}{lccccc}
\hline Modelo & Beta & $\mathbf{t}$ - estat. & Significância & Heteroscedasticidade & $\mathbf{R}^{2}$ \\
\hline$\beta_{0}(2002)$ & 0,001285 & 0,062838 & Não Significante & 0,741243 & 0,040303 \\
$\beta_{1}(2002)$ & 0,184766 & 3,367302 & Significante & 0,739021 & \\
\hline
\end{tabular}

Fonte: Elaborada pelos autores com base nos dados da pesquisa.

Essa regressão apresenta o coeficiente de intercepto não significante e sem problemas de heteroscedasticidade. O nível de explicação do investimento ficou em 4,03\%.

A fim de buscar outras relações que pudessem melhorar os resultados, optou-se por testar a variação em valores do ativo imobilizado e do crescimento das vendas, utilizando todas as 272 empresas. Nessa estimação, os resultados foram os seguintes: 
Tabela 6 - Resultados do teste do $I m v_{2002}=\beta_{0}+\beta_{1}\left(V_{2002}-V_{2001}\right)$, modelo utilizando todas as empresas

\begin{tabular}{lccccc} 
Modelo & Beta & $\mathbf{t}$ - estat. & Significância & Heteroscedasticidade & $\mathbf{R}^{2}$ \\
$\beta_{0}(2002)$ & 15660,19 & 0,289029 & Não Significante & 0,00000 & 0,637819 \\
$\beta_{1}(2002)$ & 0,435270 & 21,80561 & Significante & 0,00000 & \\
\hline
\end{tabular}

Fonte: Elaborada pelos autores, com base nos dados da pesquisa.

Nessa regressão, o coeficiente de intercepto é não significante ao nível de $10 \%$ e o modelo apresenta problemas de heteroscedasticidade. $\mathrm{O}$ nível de explicação do investimento é de $63,78 \%$. Com o objetivo de resolver o problema da heteroscedasticidade, optou-se por excluir as empresas com variação no investimento acima ou abaixo de um desvio-padrão em relação à média. No entanto, esse procedimento também não resolveu o problema.

Optou-se, então, por separar as empresas em dois grupos, com variação positiva e com variação negativa do investimento, resultando em 126 e 136 empresas respectivamente em cada amostra. Os resultados para as empresas que investiram foram os seguintes:

Tabela 7 - Resultados do teste do $I m v_{2002}=\beta_{0}+\beta_{1}\left(V_{2002}-V_{2001}\right)$, modelo utilizando as empresas com variação positiva do investimento

\begin{tabular}{lccccc}
\hline Modelo & Beta & $\mathbf{t}$ - estat. & Significância & Heteroscedasticidade & $\mathbf{R}^{2}$ \\
$\beta_{0}(2002)$ & 91751,34 & 4,176095 & Significante & 0,372452 & 0,079898 \\
$\beta_{1}(2002)$ & 0,144336 & 3,281418 & Significante & 0,366538 & \\
\hline
\end{tabular}

Fonte: Elaborada pelos autores com base nos dados da pesquisa.

A segmentação das empresas resolveu o problema da heteroscedasticidade. Os coeficientes são consistentes teoricamente e significantes ao nível de $1 \%$. O nível de explicação do investimento é de $7,98 \%$. Para as empresas que desinvestiram os resultados foram inconsistentes teoricamente.

Em razão dos resultados obtidos, optou-se por utilizar a variável crescimento das vendas defasado num período, pois, segundo Shapiro (1985), uma elevação no consumo no período precedente pode elevar os gastos com investimentos no período corrente. A função defasada proporciona um intervalo entre a decisão de investir e a efetivação dos gastos.

Nessas estimações, foi utilizada como investimento a variação dos estoques mais a variação do ativo imobilizado, em termos percentuais, de 2001 para 2002 em relação à variação das vendas de 2000 para 2001. Para a análise, foram excluídas as empresas que não apresentaram as demonstrações financeiras no período de 2000 a 2002. Após as exclusões, resultou uma amostra de 270 empresas. A equação testada foi a seguinte:

$$
\operatorname{In} v_{t}=\beta_{0}+\beta_{l}\left(V_{t-1}-V_{t-2}\right)
$$

em que:

$I n v_{t}=$ é a taxa de investimento no ano t;

$V_{t-1}=$ são as vendas das empresas no ano $\mathrm{t}-1$;

$V_{t-2}^{t-1}=$ são as vendas das empresas no ano $\mathrm{t}-2$.

Essa regressão, entretanto, não conseguiu explicar, adequadamente, as variações do investimento, talvez em razão da utilização do investimento em taxa percentual em relação ao crescimento das vendas em valores monetários. Como os resultados não foram satisfatórios, optou-se por testar a taxa de investimento em relação à taxa percentual de crescimento das vendas. A equação testada foi a seguinte:

$$
\operatorname{Inv} v_{t}=\beta_{0}+\beta_{l}\left(C V_{t-2 / t-1}\right)
$$

em que:

$I n v_{t} \quad=$ é a taxa de investimento no ano t;

$C V_{t-2 / t-1}=$ é a taxa de crescimento das vendas do ano $\mathrm{t}-2$ para o ano $\mathrm{t}-1$.

Os resultados, com os testes da equação $\operatorname{Inv}_{2002}=\beta_{0}+\beta_{1}\left(\mathrm{CV}_{2000 / 2001}\right)$ com todas as 270 empresas, foram os seguintes: 
Tabela 8 - Resultados do teste do $I n v_{2002}=\beta_{0}+\beta_{1}\left(C V_{2000 / 2001}\right)$, modelo utilizando todas as empresas

\begin{tabular}{lccccc} 
Modelo & Beta & T - estat. & Significância & Heteroscedasticidade & $\mathbf{R}^{2}$ \\
$\beta_{0}(2001)$ & 0,030661 & 1,858745 & Não Significante & 0,012477 & 0,252582 \\
$\beta_{1}(2001)$ & 0,078230 & 9,516709 & Significante & 0,012764 & \\
\hline
\end{tabular}

Fonte: Elaborada pelos autores com base nos dados da pesquisa.

Nessa regressão, o coeficiente de intercepto é significante ao nível de $10 \%$ e o nível de explicação do investimento é de $25,26 \%$. Esse modelo, porém, apresenta problemas de heteroscedasticidade. Em comparação com a utilização da variável crescimento das vendas não defasada, essa estimação conseguiu explicar melhor a variação do investimento, porém a regressão anterior não apresentou o problema da heteroscedasticidade.

Como os resultados foram insatisfatórios, testou-se, então, a variação do investimento em valores com a variação das vendas em valores. A equação testada foi a seguinte:

$$
\operatorname{Invv_{t}}=\beta_{0}+\beta_{1}\left(V_{t-1}-V_{t-2}\right)
$$

em que:

$I n v v_{t}=$ é a variação dos investimentos em valores monetários;

$V=$ são as vendas das empresas no período $\mathrm{t}-1 \mathrm{e} \mathrm{t}-2$.

Os resultados, utilizando todas as 270 empresas, são apresentados na Tabela 9:

Tabela 9 - Resultados do teste do $\ln v v_{2002}=\beta_{0}+\beta_{1}\left(V_{2001}-V_{2000}\right)$, modelo utilizando todas as empresas

\begin{tabular}{lccccc}
\hline Modelo & Beta & $\mathbf{t}$ - estat. & Significância & Heteroscedasticidade & $\mathbf{R}^{2}$ \\
\hline$\beta_{0}(2001)$ & $-146202,50$ & $-2,015603$ & Significante & 0,00000 & 0,542397 \\
$\beta_{1}(2001)$ & 1,247294 & 17,82302 & Significante & 0,00000 & \\
\hline
\end{tabular}

Fonte: Elaborada pelos autores com base nos dados da pesquisa.

Esse modelo consegue explicar $54,24 \%$ da variação dos estoques mais o ativo imobilizado. Ambos os coeficientes são significantes ao nível de $5 \%$ e o coeficiente angular do crescimento das vendas é consistente teoricamente. Essa regressão, no entanto, também apresenta problemas de heteroscedasticidade.

Como uma possível causa da heteroscedasticidade é a presença de outliers, tentou-se excluir aquelas empresas que apresentaram variação no investimento acima ou abaixo de um desvio-padrão em relação à média, resultando uma amostra de 259 empresas. Entretanto, apesar das exclusões, não se conseguiu resolver o problema.

Optou-se, então, por dividir as 259 empresas em dois grupos: as que investiram no período e aquelas que desinvestiram, resultando numa amostra de 139 e 120 empresas, respectivamente. Para as empresas que desinvestiram, os resultados foram inconsistentes teoricamente; para aquelas que investiram, os resultados foram os seguintes:

Tabela 10 - Resultados do teste do $I n v v_{2002}=\beta_{0}+\beta_{1}\left(V_{2001}-V_{2000}\right)$, modelo utilizando as empresas com variação positiva do investimento

\begin{tabular}{lccccc}
\hline Modelo & Beta & $\mathbf{t}$ - estat. & Significância & Heteroscedasticidade & $\mathbf{R}^{2}$ \\
\hline$\beta_{0}(2001)$ & 118890,60 & 5,584414 & Significante & 0,706642 & 0,085240 \\
$\beta_{1}(2001)$ & 0,143886 & 3,572956 & Significante & 0,701885 & \\
\hline
\end{tabular}

Fonte: Elaborada pelos autores com base nos dados da pesquisa. 
Essa regressão não apresenta problemas de heteroscedasticidade e os coeficientes são significativos a $1 \%$. A variação positiva do ativo imobilizado mais os estoques pode ser explicada em $8,52 \%$ pelo crescimento das vendas defasado num período.

Também foram realizados testes considerando como investimento somente a variação do ativo imobilizado em relação ao crescimento das vendas defasado num período. As equações testadas foram as seguintes:

$$
\begin{gathered}
\operatorname{Im}_{t}=\beta_{0}+\beta_{l}\left(V_{t-1}-V_{t-2}\right) \\
\operatorname{Im}_{t}=\beta_{0}+\beta_{1}\left(V_{t-2 / t-1}\right)
\end{gathered}
$$

$$
\operatorname{Im} v_{t}=\beta_{0}+\beta_{l}\left(V_{t-1}-V_{t-2}\right)
$$

em que:

$I m_{t}=$ é a variação percentual do ativo imobilizado;

$I m v_{t}=$ é a variação em valores monetários do ativo imobilizado.

Os testes, utilizando como investimento a variação percentual do imobilizado em relação à variação das vendas em valores, apresentaram resultados inconclusivos. Utilizando ambas as variáveis em taxa percentual, os resultados, com todas as 270 empresas, foram os seguintes:

Tabela 11 - Resultados do teste do $I m_{2002}=\beta_{0}+\beta_{1}\left(C V_{2000 / 2001}\right)$, modelo utilizando todas as empresas

\begin{tabular}{lccccc} 
Modelo & Beta & $\mathbf{t}$ - estat. & Significância & Heteroscedasticidade & $\mathbf{R}^{2}$ \\
$\beta_{0}(2001)$ & 0,006578 & 0,381310 & Não Significante & 0,000011 & 0,208345 \\
$\beta_{1}(2001)$ & 0,072198 & 8,398282 & Significante & 0,000015 & \\
\hline
\end{tabular}

Fonte: Elaborada pelos autores com base nos dados da pesquisa.

Essa regressão consegue explicar $20,83 \%$ da variação percentual do ativo imobilizado, porém o coeficiente de intercepto é não significante e o modelo apresenta problemas de heteroscedasticidade.
Optou-se, então, por testar a variação em valores do ativo imobilizado e das vendas. Os resultados, com todas as 270 empresas, foram os seguintes:

Tabela 12 - Resultados do teste do $I m v_{2002}=\beta_{0}+\beta_{1}\left(V_{2001}-V_{2000}\right)$, modelo utilizando todas as empresas

\begin{tabular}{cccccc} 
Modelo & Beta & $\mathbf{t}$ - estat. & Significância & Heteroscedasticidade & $\mathbf{R}^{2}$ \\
$\beta_{0}(2001)$ & $-145925,70$ & $-2,283198$ & Significante & 0,00000 & 0,537655 \\
$\beta_{1}(2001)$ & 1,088585 & 17,65371 & Significante & 0,00000 & \\
\hline
\end{tabular}

Fonte: Elaborada pelos autores com base nos dados da pesquisa.

Neste modelo, os coeficientes são significantes ao nível de $5 \%$, consistentes teoricamente, e a variação do imobilizado pode ser explicada em $53,76 \%$ pela variação das vendas defasado num período. O modelo também apresenta problemas de heteroscedasticidade.

Optou-se por separar todas as empresas em grupos que investiram e grupos que desinvestiram no período, o que resultou numa amostra de 132 empresas com variação positiva e $138 \mathrm{com}$ variação negativa. Para aquelas que investiram, considerando como investimento a variação percentual do ativo imobilizado de 2001 para 2002 em relação à variação percentual das vendas de 2000 para 2001 , obtiveram-se os seguintes resultados:

$$
\begin{gathered}
\text { Tabela } 13 \text { - Resultados do teste do } I m_{2002}=\beta_{0}+\beta_{1}\left(C V_{2000 / 2001}\right) \\
\text { modelo utilizando as empresas com variação positiva }
\end{gathered}
$$

\begin{tabular}{lccccc} 
Modelo & Beta & $\mathbf{t}$ - estat. & Significância & Heteroscedasticidade & $\mathbf{R}^{2}$ \\
$\beta_{0}(2001)$ & 0,164987 & 7,416614 & Significante & 0,664989 & 0,436813 \\
$\beta_{1}(2001)$ & 0,090378 & 10,04138 & Significante & 0,659578 & \\
\hline
\end{tabular}

Fonte: Elaborada pelos autores com base nos dados da pesquisa. 
Esse modelo está consistente teoricamente, com coeficientes significantes ao nível de $1 \%$. A regressão não apresenta problemas de heteroscedasticidade e consegue explicar $43,68 \%$ da variação positiva do ativo imobilizado pelo crescimento das vendas defasado num período. Esse resultado é, de certa forma, surpreendente, pois, como visto anteriormente, o investimento é influenciando por um elevado número de fatores, entre os quais as expectativas que variam de pessoa para pessoa. Já, para as empresas que desinvestiram, os resultados foram inconsistentes teoricamente.

Considerando como investimento a variação em valores tanto do ativo imobilizado como do crescimento das vendas, obtiveram-se os seguintes resultados para as 132 empresas que investiram:

Tabela 14 - Resultados do teste do $I m v_{2002}=\beta_{0}+\beta_{1}\left(V_{2001}-V_{2000}\right)$, modelo utilizando as empresas com variação positiva

\begin{tabular}{lccccc}
\hline Modelo & Beta & $\mathbf{t}$ - estat. & Significância & Heteroscedasticidade & $\mathbf{R}^{2}$ \\
\hline$\beta_{0}(2001)$ & $-93510,43$ & $-1,176439$ & Não Significante & 0,00000 & 0,819108 \\
$\beta_{1}(2001)$ & 1,473096 & 24,26235 & Significante & 0,00000 & \\
\hline
\end{tabular}

Fonte: Elaborada pelos autores com base nos dados da pesquisa.

Esse modelo consegue explicar $81,91 \%$ da variação do ativo imobilizado, porém apresenta problemas de heteroscedasticidade e o coeficiente de intercepto é não significativo ao nível de 10\%. Para as empresas que desinvestiram, os resultados foram inconsistentes teoricamente.

Pelos testes com o Modelo do Acelerador, percebe-se que a variação positiva do imobilizado pode ser explicada em $43,68 \%$ pelo crescimento das vendas defasado num período, com as variáveis em variação percentual. O modelo não apresenta problemas de heteroscedasticidade. O resultado corrobora a afirmação de Shapiro (1985, p. 580) de que os gastos com investimentos não são simultâneos com o aumento do consumo. Os maiores problemas ocorrem nas estimações com as empresas que desinvestiram, em que, na maioria dos casos, se en- contraram resultados inconsistentes teoricamente; quando os coeficientes foram positivos, não foi possível explicar, adequadamente, a variação negativa dos investimentos.

No quadro-resumo, a seguir, são demonstrados os principais resultados das estimações realizadas com o Modelo do Acelerador.

Como, neste trabalho, buscou-se identificar o nível de explicação do investimento e se os coeficientes estão consistentes teoricamente, os resultados apresentados ainda são válidos. Já, no caso de previsão dos gastos com investimentos, o problema deveria ser corrigido a fim de se calcularem corretamente os intervalos de confiança e as regiões de aceitação que, segundo Kmenta (1990, p. 302), em condições de heteroscedasticidade, estarão errados. 


\section{Testes}

Ano 2001 e 2002: Investimento e crescimento das vendas no mesmo ano para todas as empresas

Ano 2000 e 2002:

Investimento no ano 2002 e crescimento da vendas de 2000 para 2001 com todas as empresas

Ano 2001 e 2002: Investimento e crescimento das vendas no mesmo ano com amostra segmentada em investimento positivo e negativo.

Ano 2000 e 2002: Investimento no ano 2002 e crescimento da vendas de 2000 para 2001 com amostra segmentada em investimento positivo e negativo.

\section{Qualidade dos resultados}

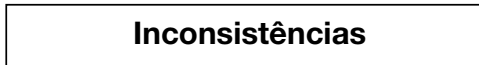

O coeficiente de intercepto foi não significante ao nível de $5 \%$ e a maioria dos testes apresentou problemas de heteroscedasticidade.

Os modelos apresentaram problemas de heteroscedasticidade.

Para as empresas que desinvestiram, os resultados foram todos inconsistentes teoricamente.

Para as empresas com investimento negativo os resultados continuaram inconsistentes teoricamente. Algumas estimações com o investimento positivo apresentaram problemas de heteroscedasticidade e coeficientes de intercepto não significantes.

Fonte: Elaborado pelos autores com base nos dados da pesquisa

\section{Quadro 1 - Principais Resultados com o Modelo do Acelerador}

\section{CONCLUSÕES}

Através dos testes com o Modelo do Acelerador conseguiu-se explicar até $54 \%$ do investimento pelo crescimento das vendas defasado num período. Pelos resultados, poder-se-ia inferir que os empresários tomam suas decisões de investimentos baseados, em grande parte, pela variação das vendas. Essas estimações, como era teoricamente esperado, apresentaram problemas de heteroscedasticidade, pois, conforme Pindyck e Rubinfeld (2004, p. 66) "a heteroscedasticidade pode ocorrer se estivermos examinando dados em corte transversal de empresas e indústrias. Pode haver motivos para acreditar que os termos de erro associados a empresas muito grandes têm variância maior do que os associados a empresas pequenas". Isso decorre do fato de que grandes empresas possuem maior renda discricionária do que as pequenas e, portanto, maior grau de liberdade em suas decisões de aplicação desses recursos. A despeito da existência de heteroscedasticidade, os resultados são válidos, pois não se está fazendo previsão dos gastos com investimentos nem teste de hipóteses, mas, sim, verificando se os coeficientes são consistentes teoricamente e se é possível explicar a variação dos investimentos através do crescimento das vendas.

Considerando as relações que não apresentaram heteroscedasticidade, obteve-se elevada corre- 
lação entre as empresas que investiram com o crescimento das vendas defasado em um período. Com esse procedimento, conseguiu-se explicar $43,68 \%$ da variação positiva do investimento. Esse percentual está bem acima do esperado para uma variável tão complexa, que é influenciada por uma série de fatores, entre os quais estão as expectativas. Além disso, esse valor é significativamente superior ao obtido por Ndikumana (1999) que foi de 22,4\% para os dados da economia americana.

Por fim, deve-se destacar que os resultados dessa pesquisa indicam uma ampla gama de possíveis estudos que permitiriam aprofundar as relações aqui estabelecidas. Esses trabalhos poderiam avaliar novas variáveis, aplicar outros procedimentos econométricos e/ou conjugar outras teorias de investimentos.

\section{REFERÊNCIAS BIBLIOGRÁFICAS}

ASSAF NETO, Alexandre. Estrutura e análise de balanços: um enfoque econômico-financeiro. 7. ed. São Paulo: Atlas, 2002.

CASAGRANDE, Elton E. As teorias keynesianas do investimento. São Paulo: Cultura Acadêmica, 2002.

DORNBUSCH, Rudiger; FISCHER, Stanley. Macroeconomia. São Paulo: McGraw-Hill do Brasil, 1982.

EXAME, SEU DINHEIRO. Não pense demais. São Paulo, abril, ano 37, n. 18-3, p. 108, 3 de set 2003.

GUJARATI, Damodar N. Econometria básica. 3. ed. São Paulo: Pearson Education do Brasil, 2000.

GORDON, Robert J. Macroeconomia. 7. ed. Porto Alegre: Bookman, 2000.

HILL, R. C.; GRIFFITS, W. E. JUDGE, G. G. Econometria. São Paulo: Saraiva, 1999.

IUDICIBUS, Sérgio de. Análise de balanços. 7. ed. São Paulo: Atlas, 1998.

JACINTO, Paulo de Andrade. O comportamento do investimento agregado no Brasil no período de 1975 a 1995. 1997. Dissertação
(Mestrado em Economia) - Faculdade de Ciência Econômicas, Universidade Federal do Rio Grande do Sul, Porto Alegre.

KMENTA, Jan. Elementos de econometria: teoria econométrica básica. 2. ed. São Paulo: Atlas, 1988.

MARION, José Carlos. Contabilidade empresarial. 9. ed. São Paulo: Atlas, 2002.

MATARAZZO, Dante C. Análise financeira de balanços: abordagem básica e gerencial. 6. ed. São Paulo: Atlas, 2003.

MERCADANTE, Aloizio. A questão do Investimento. São Paulo, 1o de jun de 2003. Disponível em: <http://www.mercadante.com. br/artigos/artigo_138html>. Acesso em: 22 set. 2003.

NDIKUMANA, Leonce. Debt service, financing constraints, and fixed investment: evidence from panel data. Journal of Post Economics, v. 21, n. 3, p. 455-478, Spring 1999.

SACHS, Jeffrey D.; LARRAIN B., Felipe. Macroeconomia. São Paulo: Makron Books, 1995.

SHAPIRO, Edward. Análise macroeconômica. 2. ed. São Paulo: Atlas, 1985.

NOTA:

Endereço dos autores:

Edson Luis Kammler

Rua Carlos Kummer, s/no - Universitário

Itapiranga - SC

89.896-000

Tiago Wickstrom Alves

Av. Unisinos, 950

São Leopoldo - RS

93.022-000

R. Cont. Fin. - USP, São Paulo, n. 39, p. 81 - 92, Set./Dez. 2005 